\title{
Application of Improved Teaching and Learning Based Algorithm for Simultaneous Optimal DG and Capacitor Placement
}

\author{
G. Balakrishna \\ Department of Electrical and Electronics Engineering, Srinivasa Ramanujan Institute of Technology, \\ Ananthapuramu \\ Email: gbk.eee@gmail.com
}

Received: 06th December 2019, Accepted: 20th January 2020, Published: 30th April 2020

\begin{abstract}
Proper electrical power distribution system design plays a vital role in delivering the good quality of electrical power to each and every consumer in the system especially end user/consumer. Good quality of electrical power is always be measured with good voltage profiles. In general, due the electrical constants of distribution system feeders, there is a considerable voltage drop due to which voltage at various buses in the distribution system will suffers from poor voltage magnitudes. This can be overcome up to some extent by various methods such as providing the compensating devices like Distributed Generators (DGs) that provides both active and reactive power injections and shunt capacitor banks, that will give reactive support to the system. In this work, an attempt has been made to obtain the optimal locations and optimal sizes of these DGs and shunt capacitors by an algorithm based on improved version of Teaching and Learning based optimization. Basically sensitivity analysis is adopted to find the optimal locations and their optimal sizes are obtained by Improved Teaching and Learning based Optimization algorithm. The proposed work has been tested with a radial distribution test systems i.e., IEEE-41bus system and results are presented.
\end{abstract}

\section{Keywords}

Distributed Generators, Improved Teaching and Learning based Optimization Algorithm, Radial Distribution System

\section{Introduction}

The configuration and structure of modern power system network is huge and it is a very complex and complicated network. The system generally consists of several electrical power generating stations of several types which are inter connected together to form a grid and connects various load centers through huge number of power transmission lines. In this conventional power system network, huge amount of electrical power is generated and supplied to various consumers through transmission and distribution lines and imparts major share in the consumer markets in the world.

In general the conventional generating stations of large capacity are remotely located with respect to load centers. Due to the larger distances between the generating stations and load centers or end consumers, huge amount of transmission and distribution losses are involved in conveying electrical power from generating stations to end users. Always there is continuous growth in electrical power demand due to increase in population and their needs. In order to meet up this increase in load demand it is required to upgrade the capacities of existing capacities of power system network, which is a hectic task and involves of lot of expenditure.

The best solution to meet increase in load demand is "Distributed Generation/Embedded Generation". Distributed Generation is a relatively emerging concept of adding small electrical power generating stations (most of them of non-conventional and renewable type) of rating ranging from few kWs to few MWs. Distributed generators are small generators situated or embedded into a power distribution network, providing the electrical power to local consumers [1-3].

These days due to latest advances and technologies in design and manufacturing of PV cells, reciprocating pumps, micro turbines, fuel cells, there is expanded range of scale of applications and opportunities for modern Distributed Generators and have made promising to meet the specific requirements of consumers to made tailor made power systems.

Most significant changes are going to occur in deregulated power systems because of the fact that, the cost of serving commercial and residential customers is greater than the cost to serving industrial customers. Therefore, the small and self contained electric generating plants normally called as Distributed Generators (DGs) can provide power to residential, commercial; in distribution feeders will be helpful and important.

In general Distributed Generators based on their functionality can be categorized as:

Type-1: DGs, those are able to generate real power only

Type-2 DGs, those are able to generate reactive power only

Type-3: DGs, those are able to generate both real and reactive powers

Type-4: DGs, that are able to generate real power and consuming reactive power 
The chief objectives of the power distribution system operation are to provide the electrical power to meet the needs of different consumers in the system most economically and reliably. In conventional electrical power systems, huge generating units that use fossil fuels, hydro, nuclear stations generates the electrical power and are situated very far away from load centers. In the present scenario production of electrical power at these stations has become loosing importance, due to the limited resources, higher transmission and distribution losses. Distributed Generators (DGs), the term generally used to represent small rating generators provides the best solution for many of these challenges.

DG can be referred as generating stations with a rating less than $10 \mathrm{MW}$, that are usually, installed in the distribution system networks [4]. At present available types of DGs includes solar plants, fuel cells, wind turbines and reciprocating engines [5]. Kumar v, et al [6] uses the cold load pick up (CLPU) to optimally place DG to have the better voltage profile. Kim KH, et al [7] reported genetic algorithm based method to determine the optimal allocation of DGs with their sizes. Zhang D, et al [8] presented a method based on improved version of tabu search method by introducing mutation operator to reduce the execution time to reduce the loss in large distribution systems. Kansal S, et al [9] has determined the optimal places for DG and capacitors based on PSO to decrease the power loss. Sajjadi SM and Haghifam [10] presented a procedure to obtain the optimal allocation of DGs and capacitors simultaneously for time varying loads.

Prommee W, et al [11] reported an algorithm based on re-initialized social structured PSO for optimal allocations of more than one DG in a micro grid. Griffin et al [12] obtained the best locations of DG units for uniformly distributed uniformly increasing load. Analytical approaches for DG placement and its size is presented in [13-15] to obtain the better voltage profile. Rama prabha D and Jayabarathi T [16] has presented an algorithm that uses an invasive weed optimization algorithm to find the optimal locations of DGs and their sizes for minimization of loss.

Monika Kumar [17] has reported a method to obtain the optimal DG sitting and their sizes based on teaching and learning based optimization by considering voltage stability. Sivasangari. R and Kamaraj N. [18] has presented a performance assessment of distribution Technologies in radial system for different varieties of DG technologies and their combinations. Nagaraju. B et al., [19] has reported a direct search algorithm to find the most favorable locations of SPV based DG for minimization of power loss.

Reza Hemmati., et al.,[20] reported numerous practical aspects in distribution system. This paper aims to reduce the investment and operational cost simultaneously by using a particle swarm optimization. Fernando Mauricio Dias. Et al., [21] has presented a planning method for distribution system network to reduce the losses and increase the reliability by taking the DGs, transformer tap setting and their size into account. Rajkumar V and Khatod DK. [22] presented an analytical approach to find the best possible locations and their sizes of DGs for loss minimization and by considering the loss saving equations. Neeraj Kanwar., et al, [23] has proposed an improved version of teaching learning based optimization to simultaneously allocate the DG sources considering multi level load scenarios.

\section{Sensitivity Analysis}

Sensitivity analysis [2] is a powerful technique that can be used to find the sensitive nodes or buses to place the devices like distributed generators or shunt capacitors. Thus sensitivity analysis gives the list of candidate locations for placing distributed generators or shunt capacitors. Estimation of these candidate locations helps in reduction of the search space considerably for any optimization procedure.

Consider a branch ' $\mathrm{j}$ ” of distribution system with $\left(R_{j}+j \cdot X_{j}\right)$ as impedance and is connected between buses ' $m$ ' and ' $n$ ' as shown in fig. 1

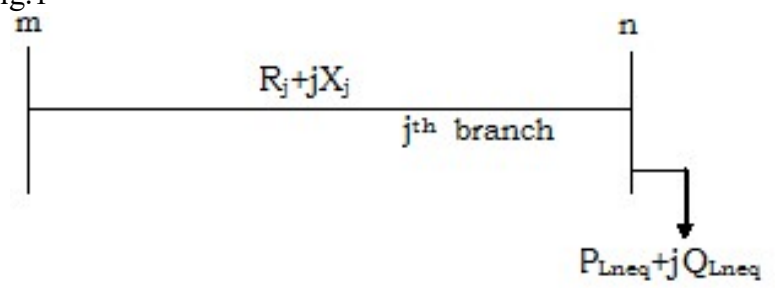

Fig. 1: Sample Line Section of Radial Distribution Systems

Real power loss in the $j^{\text {th }}$ branch connected between ' $m$ ' and ' $\mathrm{n}$ ' can be observed as

$P_{\text {loss }}=R_{j} \times\left[\frac{P_{\text {lneq }}^{2}+Q_{\text {Lneq }}^{2}}{V_{n}^{2}}\right]$

Where, $P_{\text {Lneq }}$ is sum of real power at bus 'n' and real power of all the buses beyond node 'n', $Q_{\text {Lneq }}$ is sum of 
reactive power at bus ' $n$ ', and reactive power of all the buses beyond node ' $n$ '.

The loss sensitive factor of bus 'n', i.e., real power loss with respect to real power flow can be calculated with the equation

$$
\frac{\partial P_{\text {loss }}}{\partial P_{\text {Lneq }}}=2 \times\left(\frac{P_{\text {Lneq }}}{V_{n}^{2}}\right) R_{j}
$$

Using the equation (2), loss sensitive factors are evaluated for all buses from the distribution load flow and these buses are arranged in descending order. The buses at the top of this list are more sensitive with respect to real power loss and hence these buses can be chosen to install DG units to minimize the real power loss.

The loss sensitive factor of bus ' $n$ ', i.e., real power loss with respect to reactive power flow can be calculated with the equation

$$
\frac{\partial P_{\text {loss }}}{\partial Q_{\text {Lneq }}}=2 \times\left(\frac{Q_{\text {Lneq }}}{V_{n}^{2}}\right) R_{j}
$$

Using the equation (3), loss sensitive factors are evaluated for all the buses from the distribution load flow and these values are arranged in decreasing order. The buses at the top of this list are more sensitive with variation of real power losses with respect to reactive power flow and hence these buses can be chosen to install capacitor units to minimize the real power loss.

\section{Problem Formulation and Objective Function Problem Formulation:}

In this work, the main problem considered is to find the optimal locations and optimal sizes of Distributed Generators (DGs) and shunt capacitor banks that will minimizes the power losses of the system subjected to a set of practical constraints.

In this work, optimal locations of the DGs as well as shunt capacitor banks are obtained by conducting sensitivity analysis. The optimal sizes of these units are obtained by proposed ITBLO algorithm.

\section{Objective Function:}

\section{Minimization of real power loss:}

Minimization of real power loss can be considered as first objective function, the real power loss at any stage of the problem is calculated by using the formula given below and is obtained by using distribution load flow based on forward backward sweep algorithm.

$$
f_{1}(x)=P_{L}(x)=\sum_{i=1}^{N_{b r}}\left|I_{i}\right|^{2} \times R_{i}
$$

Where $R_{i}$ is the resistance of branch ' $i$ ', 'Ii' is the magnitude of current through branch ' $i$ ' and $\mathrm{N}_{\mathrm{br}}$ is the number of branches of radial distribution system.

\section{Constraints:}

(i) Power flow balance:

$$
\begin{aligned}
& P_{i}=\sum_{i=1}^{N_{b r}} V_{i} \cdot V_{j} \cdot Y_{i j} \cdot \operatorname{Cos}\left(\theta_{i j}-\delta_{i}-\delta_{j}\right) \\
& Q_{i}=\sum_{i=1}^{N_{b r}} V_{i} \cdot V_{j} \cdot Y_{i j} \cdot \operatorname{Sin}\left(\theta_{i j}-\delta_{i}-\delta_{j}\right)
\end{aligned}
$$

(ii) Voltage magnitude constraint:

Voltage at each bus should be within the individual limits even after placing a DG and/or capacitor, it should be greater than $V_{\min }$ and less than $V_{\max }$ and is represented as

$V_{\min } \leq V_{j} \leq V_{\max }$

(iii) Feeder capability constraint:

The magnitude of the current through all the line sections should be within the acceptable limits of the respective branch i.e.,

$I_{k} \leq I_{k}^{\max }, k \in\{1,2,3 \ldots . . l)$

Where $I_{k}^{\max }$ is maximum current carrying capacity of branch $k$ 
(iv) Distributed Generator Constraints:

If a DG unit is installed at bus ' $i$ ', its active and reactive power generations should be within the DG units capacity limits; otherwise these values should be equal to zero. Mathematically, this constraint can be developed as:

$W_{i} . P_{G, i}^{\min } \leq P_{G, i} \leq W_{i} \cdot P_{G, i}^{\max } \quad i \in N$ and $i \neq S u b$

A binary variable $W_{i}$ is used to describe the installation of DG on bus ' $i$ '. When a DG unit is installed at bus ' $i$ ', $W_{i}=1$ other wise $W_{i}=0$

(v) Shunt Capacitor Constraint:

If a shunt capacitor bank is installed at bus ' $i$ ', its reactive power rating should be with the kVAr rating of the capacitor bank. Mathematically this can be:

$Q_{C, i}^{\min } \leq Q_{C, i} \leq Q_{C, i}^{\max }$

Implementation with itlbo Algorithm

The proposed ITLBO algorithm is implemented to solve optimal sitting and sizing of DG and capacitor units problem. Here, minimization of power loss is considered as an objectives and is solved while satisfying system constraints. The step by step implementation is described as follows:

Step 1: Initialize the problem parameters and read system data.

Step 2: Define the problem search space to find the solution.

Step 3: Initial population is generated randomly for the control parameters within their limits.

Step 4: The system bus and line data is updated with the generated new population.

Step 5: Perform distribution load flow and calculate the system loss and fitness values of each of the populations.

Step 6: Select initial population as teachers and treat the remaining population as learners and increase the iteration count.

Step 7: Assign the learners to teachers and form the groups.

Step 8: Calculate the teaching factor for each of the teachers in each of the groups.

Step 9: Generate new population in teachers. Using this population, calculate the objective and fitness values and identify the best solution from the results.

Step 10: Generate new population in learners phase. Using this population, calculate the objective and fitness values.

Step 11: Repeat the steps from 6 to 10 for a predefined number of iterations or a convergence condition is satisfied

Step 12: Output the results and identify the best solution.

\section{Results with Analysis}

The proposed method is tested on standard IEEE-41 bus test systems results are presented.

Here in this work, two generators each of $1000 \mathrm{~kW}$ operating at a power factor of 0.8 lag and two capacitors each of maximum capacity of $500 \mathrm{kVAr}$ are used.

An IEEE-41 bus radial distribution system shown in fig. 2, consisting of 41 buses or nodes and 40 lines with one sub stations is considered here as test system.

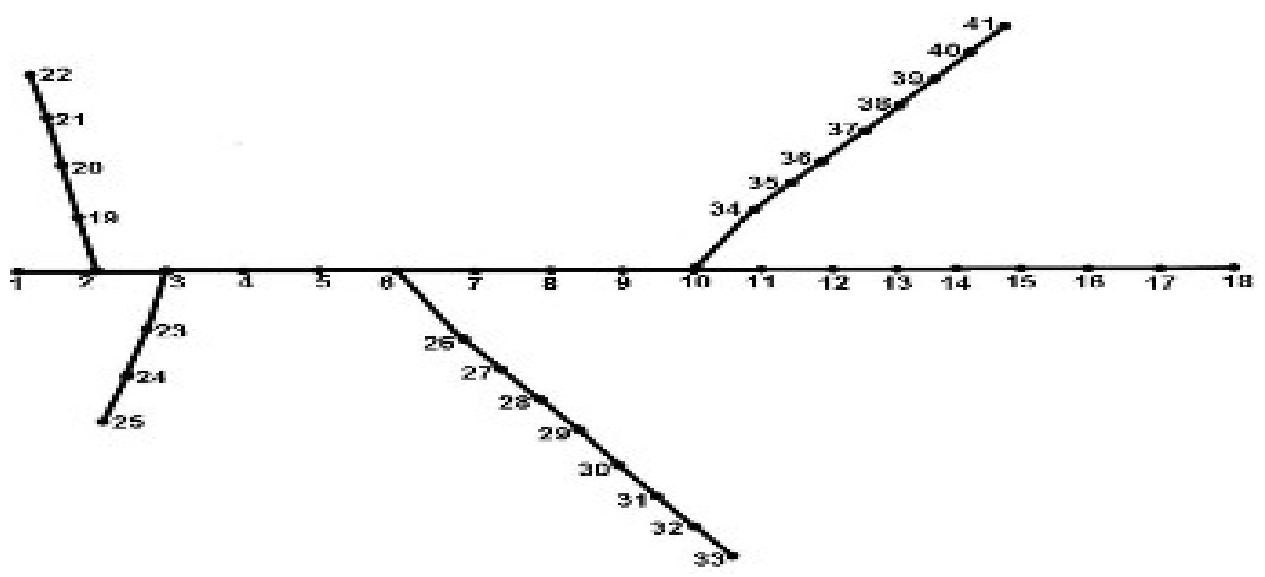

Fig.2: IEEE-41 Bus Radial Distribution System 
Proposed ITLBO algorithm has been tested for four cases as

Case-1: Base case (original system)

Case-2: System with optimal placement of DGs without capacitors

Case-3: System with optimal placement of capacitors without DGs

Case-4: Simultaneous placement of DGs and capacitors

Table 1: Simulation Results of ITLBO for Four Cases

\begin{tabular}{|c|c|c|c|c|c|}
\hline S. No. & Aspect & $\begin{array}{l}\text { Without } \\
\text { DG }\end{array}$ & $\begin{array}{l}\text { With DG } \\
\text { only }\end{array}$ & $\begin{array}{c}\text { With } \\
\text { capacitors only }\end{array}$ & $\begin{array}{l}\text { With both DGs } \\
\text { and Capacitors }\end{array}$ \\
\hline 1 & $\begin{array}{c}\text { Optimal location of first } \\
\text { DG } \\
\text { (Bus Number) }\end{array}$ & - & 7 & - & 7 \\
\hline 2 & $\begin{array}{l}\text { Optimal size of the } \\
\text { first } \mathrm{DG}(\mathrm{kW})\end{array}$ & - & 622.34 & - & 472.33 \\
\hline 3 & $\begin{array}{l}\text { Optimal location of } \\
\text { second DG } \\
\text { (Bus Number) }\end{array}$ & - & 11 & - & 11 \\
\hline 4 & $\begin{array}{c}\text { Optimal size of second } \\
\text { DG }(\mathrm{kW})\end{array}$ & - & 519.79 & - & 357.64 \\
\hline 5 & $\begin{array}{c}\text { Optimal location of first } \\
\text { Capacitor bank (Bus } \\
\text { Number) }\end{array}$ & - & - & 30 & 30 \\
\hline 6 & $\begin{array}{l}\text { Optimal size of the first } \\
\text { Capacitor bank (kVAr) }\end{array}$ & - & - & 478.36 & 387.39 \\
\hline 7 & $\begin{array}{c}\text { Optimal location of } \\
\text { second } \\
\text { Capacitor Bank (Bus } \\
\text { Number) }\end{array}$ & - & - & 38 & 38 \\
\hline 8 & $\begin{array}{l}\text { Optimal size of second } \\
\text { capacitor bank (kVAr) }\end{array}$ & - & - & 287.39 & 427.33 \\
\hline 9 & Power Loss $(\mathrm{kW})$ & 801.17 & 427.91 & 684.29 & 314.94 \\
\hline 10 & $\begin{array}{l}\text { Minimum voltage } \\
\text { (p.u.) }\end{array}$ & 0.9142 & 0.9455 & 0.9511 & 0.9607 \\
\hline
\end{tabular}

Case-1: Base Case:

In case-1, the system losses and voltage profiles have been obtained by distribution load flow without considering the inclusion of Distributed Generators and shunt capacitor banks. It is found from the simulation results that the real power losses are $801.17 \mathrm{~kW}$ and the minimum voltage of the system is observed to be 0.9142 p.u found at bus number 41 .

\section{Case-2: System with optimal placement of DGs:}

In case-2, the system is considered with optimal sitting and sizing of DGs without using the shunt capacitor banks. Initially sensitivity analysis is conducted to obtain the loss sensitive factors in which variation of real power flow with respect to real power flow for all the buses and is arranged in the descending order. The buses having highest loss sensitive factors are chosen to install DG units. The results of sensitive analysis for IEEE-41 bus system for case- 2 given away in fig. 3 . 


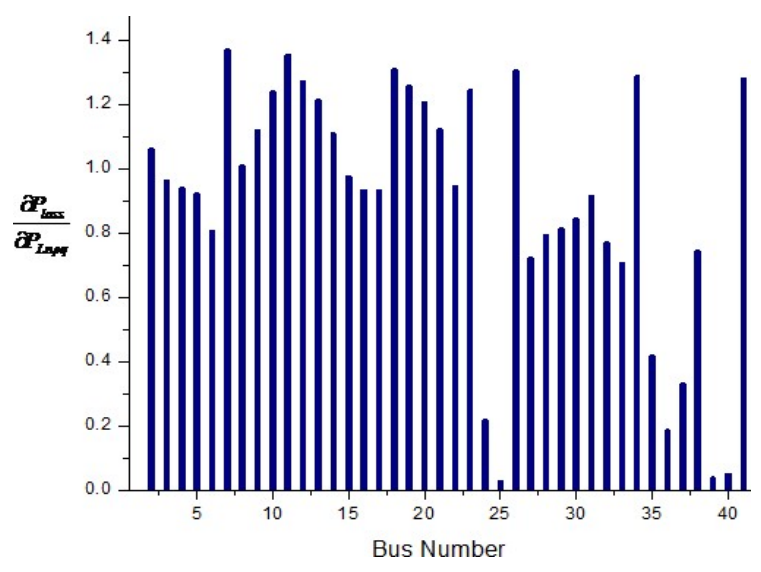

Fig.3: LSFs of IEEE-41 Bus System for Case-2

It is observed that, bus numbers 7 and 11 have highest Loss sensitive factors (LSFs), therefore these buses are chosen to install DG units. From the simulation results it is observed that the real power loss has been reduced from $801.17 \mathrm{~kW}$ to $427.91 \mathrm{~kW}$ and minimum voltage has been increased from 0.9142 to 0.9455 . The convergence characteristics of ITLBO are shown in figure. 4.

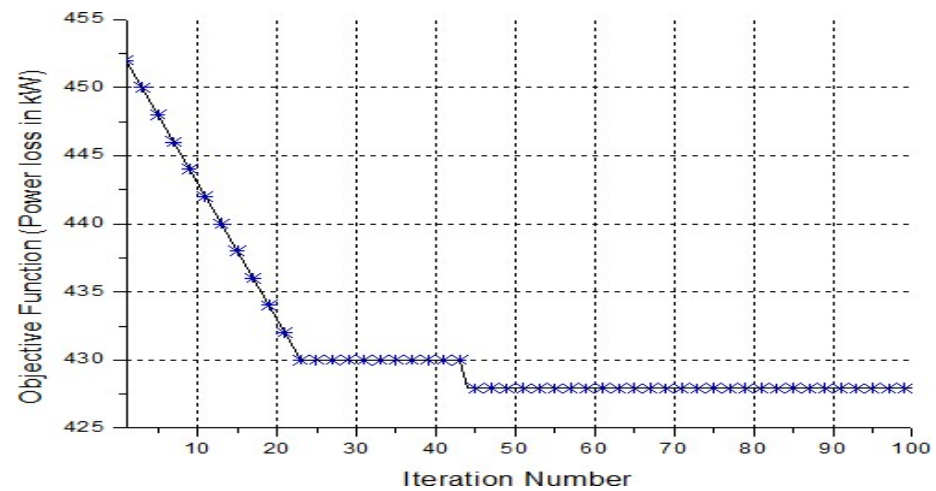

Fig. 4: Convergence Characteristics of ITLBO for IEEE-41 bus Radial Distribution System for Case-2

Case-3: System with Optimal placement of shunt capacitor banks:

In this case, the system is considered with optimal sitting and sizing of the shunt capacitors without using DGs. Initially sensitivity analyses is conducted to obtain the loss sensitive factors in which variation of real power

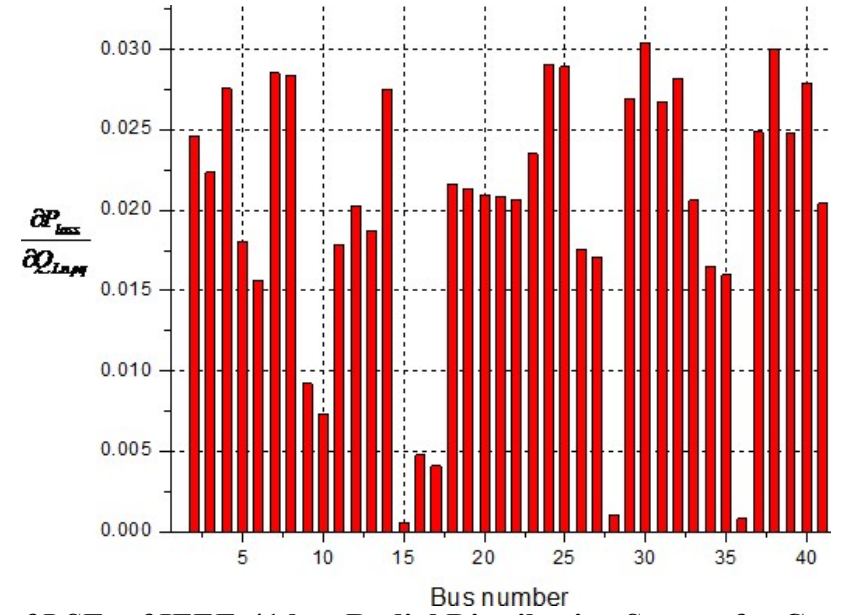

Fig. 5: Variation of LSFs of IEEE-41 bus Radial Distribution System for Case-3

flow with respect to reactive power flow for all the buses and are arranged in the descending order. The buses 
having highest loss sensitive factors are chosen to install DG units. The results of sensitive analysis for IEEE-41 bus system for case- 3 are shown in fig. 5 .

It is observed that, bus numbers 7 and 11 have highest Loss sensitive factors (LSFs), therefore these buses are chosen to install DG units. From the simulation results it is observed that the real power loss has been reduced from $801.17 \mathrm{~kW}$ to $684.29 \mathrm{~kW}$ and minimum voltage has been increased from 0.9142 to 0.9511 p.u. The convergence characteristics of ITLBO are shown in figure.6. It is also observed that when capacitors are used in the system the reactive support made the voltage profile better when compared to the voltage profile with DG units only.

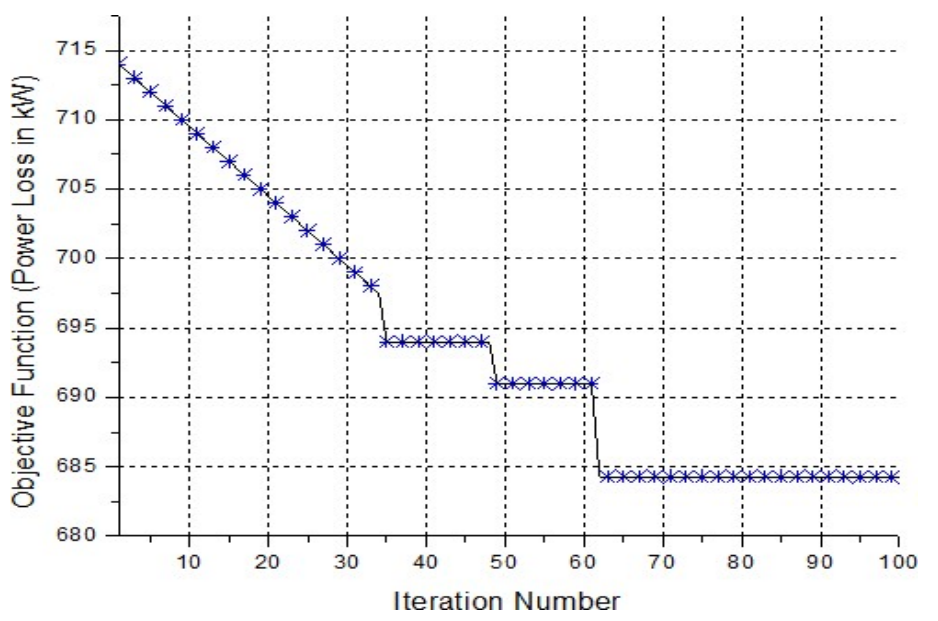

Fig. 6: Convergence Characteristics of ITLBO for IEEE-41 Bus Radial Distribution System for Case-3

\section{Case-4: System with Optimal placement of both DGs and shunt capacitor banks:}

In this case, the system is considered with optimal sitting and sizing of both DGs and shunt capacitors. As per the sensitivity analysis bus numbers 7 and 11 are selected to install DG units and bus numbers 30 and 38 are selected to include shunt capacitor banks. From the simulation results it is observed that the real power loss has been reduced from $801.17 \mathrm{~kW}$ to $314.94 \mathrm{~kW}$ and minimum voltage has been increased from 0.9142 to 0.9607 p.u. The convergence characteristics of ITLBO are shown in figure. 7.

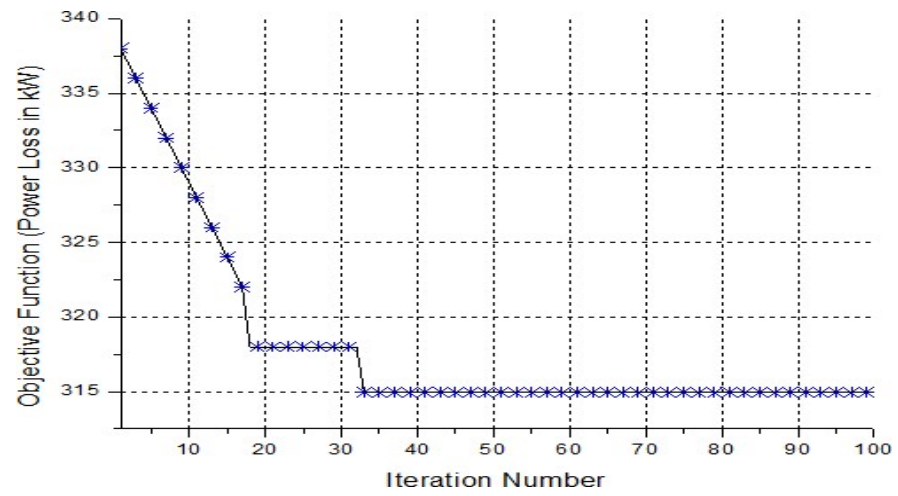

Fig. 7: Convergence Characteristics of ITLBO for IEEE-41 Bus Radial Distribution System for Case-4

\section{Conclusions}

In this work a methodology based on Improved Teaching and learning based Optimization (ITLBO) is proposed and tested on standard IEEE-41 bus radial distribution system. For this test system the optimal locations of DGs and shunt capacitor banks are found by sensitivity analysis and their optimal sizes are found by ITLBO algorithm. In this work the analysis is carried out for different combinations of DGs and shunt capacitors and results are presented. From the obtained simulation results, it is observed that proper location of DGs and shunt capacitor banks with their optimal sizes in the distribution system reduces the losses and improves the voltage profile effectively if they are used simultaneously. 


\section{References}

[1] Wang P and Billinton R. "Demand-side optimal selection of switching devices in radial distribution system planning”, IEE Proceedings Generation, Transmission and Distribution, 1998, 145(4): 409-414.

[2] Prakash. K and M. Sydulu, "Particle swarm optimization based capacitor placement on radial distribution systems," in Proc. IEEE Power Engineering Society General Meeting, 2007, pp. 1-5.

[3] Ghasemi Mojtaba, Ghavidel Sahand, Rahmani Shima, Roosta Alireza, Falah Hasan, "A novel hybrid algorithm of imperialist competitive algorithm and teaching learning algorithm for optimal power flow problem with non-smooth cost functions", Eng Appl Artif Intell 2014;29:54- 69.

[4] CIGRE: "Impact of increasing contribution of dispersed generation on the power system. Working group 37.23; 1999.

[5] EL. Khattam W, et al "Distribution system planning using distributed generation". Proceedings of IEEE Canadian conference on electrical and computer engineering, Canada vol.1; 2003, pp 579-582.

[6] Kumar V., et al "DG integrated approach for service restoration under cold load pick up". IEEE transaction on power delivery 2010; 25, pp398-406.

[7] Kim KH, et al, "Dispersed generator placement using fuzzy- genetic algorithm in distribution systems. Proceedings of IEEE power engineering society summer meeting, USA, vol.2; 2002 pp 1148-1153.

[8] Zhang D, Fu Z, Zhang I., "An improved tabu search algorithm for loss minimization reconfiguration in large scale distribution systems”. Elec. Pow. Sys. Res. 2007; 77(5-6); 685- 94.

[9] Kansal S, Kumar V, "Composite active and reactive power compensation of distribution networks". $7^{\text {th }}$ IEEE International conference on industrial and information systems, IIT Madras, 2012, pp 1-6.

[10] Sajjadi SM., et al "Simultaneous placement of DG and capacitors in distribution networks considering voltage stability index". Int. journ. of electrical power energy systems 2013; 46:366-75.

[11] Prommee W., et al "Optimal multiple distributed generation placement in micro grid system by impro. reinitialized social structures PSO”. Europ. Trans Elec. Pow. 2011; 21(1); 489.

[12] Griffin., et al "Placement of dispersed generation systems for reduced losses" Proceedings of $33^{\text {rd }}$ annual Hawaii int. conf. on system sciences, Maui; 2000. pp. 1-9.

[13] Wang C., et al "analytical approach for optimal placement of DG sources in power systems". IEEE trans powr syst 2004; 4; pp. 2068-76.

[14] Acharya N., et al "An analytical approach for DG allocation in prim distribution network". Elec. Power energy system 2006; 28 (10); 669-78.

[15] Gozel T., et al "An analytical method for the sizing and sitting of distributed generators in radial systems”. Electr powr sys res 2009; 79;912-918.

[16] Rama prabha D and Jayabarathi T, "Optimal placement and sizing of multiple distributed generating units in distribution networks by invasive weed optimization algorithm, Ain Shams Engg. Journal, 2015.

[17] Monika kumara, "Distributed generation planning using teaching learning based optimization with voltage stability consideration”, Global journal of engineering science and researches, Volume, 10, issue 2, October, 2015.

[18] Sivasangari. R, Kamaraj N. "Performance assessment of distributed generation technologies in radial distribution system", Journal of Rev. Tec Univ. Zulia, Vol.38, No.3, pp.94-106, 2015.

[19] B. Nagaraju., et al "Optimal placement of SPV based DG for loss reduction in radial distribution system using direct search algorithm”, Int. journal of conceptions on Elec. And Electronics Engg, Vol, 3, Issue, 1, April 2015.

[20] Reza Hemmati., et al., "Distribution network expansion planning and DG placement in the presence of uncertainties”, Journal of Elec. Power and Energy Sys. 73, pp. 665-673,2015.

[21] Fernando Mauricio Dias., et al., "Distribution networks planning using decomposition optimization technique", IET Journal, Vol.9, Iss.12 pp.1409-1420, 2015.

[22] Rajkumar Viral and Khatod D.K., Än analytical approach for sizing and sitting of DGs in balanced radial distribution networks for loss minimization", Journal of Electrical Power and Energy systems, No. 67, pp.191-201, 2015.

[23] Neeraj Kanwar., et al., "Simultaneous allocation of distributed resources using improved teaching learning based optimization”, Energy Conversion and management, No. 103, pp.387 to 400, 2015. 